\title{
Rapid Descriptive Consumer Analysis Using Simultaneous and Monadic Sample Presentation for Coffee
}

\author{
Chloe N. Stokes, Joseph P. Kerry, Maurice G. O’Sullivan* \\ The Food Packaging Group, School of Food and Nutritional Sciences, University College Cork, Cork, Ireland \\ Email: *maurice.osullivan@ucc.ie
}

How to cite this paper: Stokes, C.N., Kerry, J.P. and O'Sullivan, M.G. (2018) Rapid Descriptive Consumer Analysis Using Simultaneous and Monadic Sample Presentation for Coffee. Food and Nutrition Sciences, 9, 63-76.

https://doi.org/10.4236/fns.2018.92005

Received: January 9, 2018

Accepted: February 4, 2018

Published: February 7, 2018

Copyright $\odot 2018$ by authors and Scientific Research Publishing Inc. This work is licensed under the Creative Commons Attribution International License (CC BY 4.0).

http://creativecommons.org/licenses/by/4.0/

\begin{abstract}
The objective of this study was to investigate how rapid descriptive consumer analysis using simultaneous presentation of samples compared with monadic presentation of samples, using both affective and descriptive sensory evaluation methods. Simultaneous presentation of coffee samples for sensory acceptance testing, using ranking analysis, was conducted using naïve assessors. In a separate session, assessors evaluated the same coffee samples, using monadic presentation and employing the same scales. Similarly, descriptive consumer analysis, using simultaneous and monadic sample presentation, was conducted using descriptive attributes chosen by the panel. For RDA (Ranking descriptive analysis), coffee samples were presented simultaneously (randomised) to assessors and subsequently ranked. The process was then repeated using the same assessors; however, samples were presented in monadic and randomised presentation order. Data accumulated from the study were analysed by Analysis of Variance (APLSR-ANOVA Partial Least Squares Regression). Results obtained indicate that simultaneous presentation of samples was more effective than monadic presentation, as a larger amount of attributes with significant $(P<0.05)$ intensity differences were observed using RDA. Thus, simultaneous presentation of samples also allows ranking in SAT evaluation and proved a useful tool in establishing the hedonic attributes of products. We propose to call this method Ranking Acceptance Analysis (RAA).
\end{abstract}

\section{Keywords}

Sensory, Hedonic, Descriptive, Ranking, Coffee

\section{Introduction}

RDA is a modification of flash profiling developed by Richter et al. [1]. In flash 
profiling, the lexicon is developed in a free-choice type manner, but with RDA, this is developed with a consensus list produced similarly to traditional descriptive methods; consequently, there is no issue with differences in semantic consensus as described to be the case for flash profiling. For both methods, all samples are presented simultaneously so that they can be ranked, as opposed to the monadic presentation of traditional methods. Richter et al. [1], evaluated how chocolate puddings with different sweetener and sugar contents were analysed using Quantitative Descriptive Analysis (QDA), Free-choice profiling (FCP) and RDA. They reported that RDA method produced results similar to the results obtained using QDA and FCP.

Various rapid sensory methods currently exist which include Flash Profiling, RDA, Free Sorting, Off-Flavour Quantification, Polarized Sensory Positioning (PSP), Optimized Sensory Profiling Method, Project Mapping: Napping, Justabout-right scales, Ranked-Scaling, Temporal Dominance of Sensations (TDS), Check-all-that-apply (CATA) and The Ideal Profile Method (IPM) [2]. O'Sullivan et al. [2] states that it is claimed these methodologies can be used with semitrained assessors and even naïve assessors, providing results are close to those obtained by classic descriptive analysis and their trained panels.

According to Kim and O'Mahony [3], the rank-rating method does not avoid forgetting intensities and ratings of prior stimuli, however, in contrast, the conventional descriptive method avoids forgetting ratings given to stimuli and it doesn't avoid forgetting the intensities of prior stimuli. As a consequence, untrained assessors are able to discriminate between samples much more efficiently using the ranking procedure.

SAT (Sensory Acceptance Testing) combined with simultaneous RDA with the resulting data analysed by multivariate data analysis is an approach that has been successfully demonstrated for a number of products including: Chocolate pudding [1], White pudding [4] [5], Black Pudding [6] [7], Butter [8], and Mozzarella cheese [9].

The objective of this study was to evaluate the cognitive differences of simultaneous sensory assessment of test samples, as performed by RDA, compared to the monadic presentation of the same samples using the same scales. The same procedure was followed to investigate monadic (standard) and simultaneous presentation in a classical SAT. SAT was investigated prior to descriptive analysis to eliminate any bias. In essence we wished to determine if assessors perceived coffee samples similarly using simultaneous or monadic presentation for both affective and descriptive methods.

\section{Materials and Methods}

\subsection{Coffee Sample}

A total of four different coffee samples were used in this trail. Two ground-roasted coffee samples and two instant coffee samples were used which are also the leading brands in the Republic of Ireland, but which also display a range of cof- 
fee strengths reflected by the different TDS (Total dissolved solids) values (Table 1). The coffee samples were bought in a local supermarket in the Republic of Ireland. Each coffee sample had the same expiry date and was purchased from the same store simultaneously. The coffee was stored in a cool dry area at room temperature until the trial commenced. Each sample was freshly opened on each trial day.

\subsection{Sample Preparation}

Each coffee was prepared following the preparation protocol outlined below to ensure coffee samples were standardised throughout the trial.

The standardised preparation protocol for ground roasted filter coffee (cafetière/french press) is as follows:

A kettle (Morphy Richards 1.7 L jug kettle) was filled with water and boiled to $100^{\circ} \mathrm{C}$. The National Coffee Association USA [10] recommends that the water used for coffee brewing should be in the range of $90.6^{\circ} \mathrm{C}-96.1^{\circ} \mathrm{C}$. Thus, once the temperature of the water in the kettle decreased to $95^{\circ} \mathrm{C}\left( \pm 1^{\circ} \mathrm{C}\right)$ the cafetière (Grunmerg $0.4 \mathrm{~L}$ stainless steel cafetière) was warmed by filling it with approximately $130 \mathrm{ml}$ of boiled water and swirling the water around for $10 \mathrm{sec}$ prior to disposing of the water. Fresh ground-roasted coffee (12.5 g) was then placed into the warmed cafetière as international standards suggest a ratio of $5-9 \mathrm{~g}$ coffee per $100 \mathrm{ml}$ of water [10]. The cafetière was filled with approx. $250 \mathrm{ml}$ of the boiled water and the contents were stirred using a metal tablespoon. After a three-min extraction period, the cafetière plunger was pressed down on contents and approx. $177 \mathrm{ml}$ of the brewed coffee was poured into $237 \mathrm{ml}$ paper-based cups (methyl cellulose internally and externally coated with polyethylene). Once the contents of the cup reached a temperature of $70.8^{\circ} \mathrm{C}\left( \pm 1^{\circ} \mathrm{C}\right)$, they were served to assessors.

The standardised preparation protocol for instant coffee is as follows:

A kettle was filled with water and boiled to $100^{\circ} \mathrm{C}$. Once the temperature of the water in the kettle decreased to $95^{\circ} \mathrm{C}\left( \pm 1^{\circ} \mathrm{C}\right)$ instant coffee $(1.85 \mathrm{~g})$ was placed into a $237 \mathrm{ml}$ paper-based cup (methyl cellulose internally and externally coated with polyethylene). The boiled water (approx. $177 \mathrm{ml}$ ) was added to the paper-based cup and the contents were stirred using a metal spoon. Once the contents of the cup reached a temperature of $70.8^{\circ} \mathrm{C}\left( \pm 1^{\circ} \mathrm{C}\right)$, coffee samples were served to assessors.

Table 1. Codes present on the PLS plot and the ANOVA value table.

\begin{tabular}{ccc}
\hline Code & Description & \% TDS \\
\hline C1 & Manufactured from a blend of soluble coffee and finely ground coffee & 0.87 \\
C2 & Manufactured from a blend of soluble coffee and finely ground coffee & 0.91 \\
C3 & Manufactured from 100\% Arabica ground-roasted coffee beans & 0.86 \\
C4 & Manufactured from 100\% Arabica ground-roasted coffee beans & 0.81 \\
\hline
\end{tabular}

${ }^{\star}$ Percentage total dissolved solids. 


\subsection{Sensory Acceptance Testing}

The SAT [11] [12] [13] was conducted using naïve assessors $(n=28)$ for both RAA and for monadic presentation, who were all regular coffee consumers. Assessors were aged between 22 - 64 years old. Stone et al. [13] state that this ranking test can be performed with as little as 24 assessors if all the assessors evaluate all the products. This is the case with the presented paper. However the data obtained becomes statistically stronger the greater the number of assessors used, and up to 75 may be used. The greater the number of subjects used in a test the less the likelihood of Type I and Type II errors occurring. Additionally all analysis was conducted in duplicate and significantly increasing the validity of results [12] [13]. Therefore each sample was tested 56 times for each hedonic attribute. Assessors used the sensory hedonic descriptors in Table 2 to evaluate the four different coffee samples. Each assessor was asked to indicate their degree of liking on a $10-\mathrm{cm}$ continuous line scale ranging from 0 (extremely dislike) at the left to 10 (extremely like) at the right and rating subsequently scored in $\mathrm{cm}$ from left. For RAA, the four coffee samples were presented simultaneously and assessors ranked the samples together on the same scoring sheet, thus ranking samples amongst each other. Samples were presented simultaneously, but in a random order to prevent first order and carry-over effects [14]. For the monadic acceptance test method, the four coffee samples were presented randomised to the naïve assessors $(n=28)$ who evaluated the four coffee samples, monadically, where samples were evaluated once, then removed prior to the next sample being presented to the assessor. Samples were scored on individual scoring sheets. For both presentation methods analysis was conducted in duplicate. For SAT, a total of four sessions were carried out as all samples were evaluated in duplicate (two sessions where the four samples were presented simultaneously and two sessions where four samples were presented monadically to assessors).

Table 2. Attribute list evaluated [20].

\begin{tabular}{|c|c|}
\hline Attribute & Definition \\
\hline Liking aroma & How likable is the aroma \\
\hline Liking flavour & How likable is the flavour \\
\hline Overall acceptability & Overall acceptance of the sample \\
\hline Coffee aroma & The unique smell associated with coffee products \\
\hline Coffee flavour & Overall intensity of coffee flavour \\
\hline Roasted/burnt flavour & The flavour descriptor similar to that found in burnt food \\
\hline Earthy flavour & $\begin{array}{l}\text { Reminiscent of raw potato flavour and the odour associated } \\
\text { with fresh earth, wet soil or hummus Undesirable in coffee }\end{array}$ \\
\hline Fruity flavour & Reminiscent of fruit flavour \\
\hline Sweet taste & $\begin{array}{c}\text { Fundamental taste sensation of which sucrose is typical. } \\
\text { Generally associated with sweet aroma descriptors } \\
\text { such as fruity, chocolate and caramel }\end{array}$ \\
\hline Bitter taste & $\begin{array}{l}\text { A primary taste characterised by a solution of caffeine, quinine and } \\
\text { certain alkaloids. The taste is considered desirable up to a certain } \\
\text { level and is affected by the degree of roast brewing procedures }\end{array}$ \\
\hline
\end{tabular}




\subsection{Descriptive Analysis}

Assessors $(n=28)$ evaluated the same four coffee samples, as for the SAT, using descriptive analysis. Samples were presented to assessors simultaneously and RDA was conducted. Richter et al. [1] suggested that when time is insufficient to train a panel, the use of an untrained panel and a ranking test should be considered (but employing a minimum of 21 assessors). In the present study, naïve assessors ( $n=28$ for simultaneous presentation and $n=28$ for monadic presentation) were used to undertake the RDA, but were given basic instructions for understanding the descriptive attribute definitions (as outlined in Table 2) and how to use the $10-\mathrm{cm}$ continuous line scale. The scale was anchored with "non-extreme" (0) at the left to "extreme" (10) at the right.

For RDA, the assessors were presented with all samples (randomised) and asked to evaluate the first four attributes coffee aroma, coffee flavour, roasted/ burnt flavour and earthy flavour. Samples were then replaced and assessors evaluated the final three attributes which included fruity flavour, sweet taste and bitter taste.

For the monadic descriptive test method, each sample was presented randomised to assessors one at a time, and once a sample had been evaluated, it was removed prior to the second sample being presented to the assessor. For descriptive analysis, a total of four sessions were carried out as all samples were evaluated in duplicate. Acceptance testing was conducted prior to the descriptive testing in an attempt to reduce bias.

\subsection{Standardised Presentation Protocol}

The four coffee samples presented to assessors were identical in terms of presentation in order to avoid any possible bias that might have occurred. Each of the samples (each approx. $177 \mathrm{ml}$ ) were presented to assessors in $237 \mathrm{ml}$ light brown, single-walled, paper-based cups (methyl cellulose internally and externally coated with polyethylene) and at $70.8^{\circ} \mathrm{C}\left( \pm 1^{\circ} \mathrm{C}\right)$. A three-digit random code was present on the outside of each of the cups for identification. A temperature probe (model: testo 110 . Tolerable margin of error $\pm 1^{\circ} \mathrm{C}$. Supplied by Testo, AG, Germany) was used to confirm the temperature of each sample prior to analysis. Samples were presented in random order to prevent possible carryover effects. All samples were served black, and no condiments were allowed to be added to the coffee samples.

\subsection{Sensory Evaluation}

Sensory analysis sessions were conducted in University College Cork's sensory evaluation laboratory which conforms to international standards [15] under white light at room temperature. All samples were evaluated in duplicate for both acceptance testing and descriptive testing for both monadic and simultaneous presentation. Therefore, a total of eight sessions were carried out to complete this study (four sessions per presentation method) which involved one session per day. 
Deionised water was provided and assessors were instructed to sip the deionised water between samples to cleanse their palate. The duration of each session varied, but as anticipated, the sessions where the samples were presented to assessors simultaneously took the least amount of time. Acceptance testing took approx. 25 - $45 \mathrm{~min}$ and descriptive testing took approx. 35 - $60 \mathrm{~min}$. In contrast, when the samples were presented individually to assessors, acceptance testing took approx. 35 - $60 \mathrm{~min}$ and descriptive testing took approx. $1-1.30 \mathrm{hr}$ ).

\subsection{Percentage Total Dissolved Solids (\% TDS)}

Three readings were taken from three different samples and an average was calculated from these samples. The method used was as follows:

An ice bath was prepared. The Refractometer (VST inc digital refractometer from SCAE store, Essex, UK) was calibrated using distilled water. A kettle was used to boil water $\left(100^{\circ} \mathrm{C}\right)$ and a thermometer (model: testo 110 . Tolerable margin of error $\pm 1^{\circ} \mathrm{C}$. Supplied by Testo AG, Germany) was used to monitor the temperature after boiling and once the temperature of the water reached $95^{\circ} \mathrm{C}$ $\left( \pm 1^{\circ} \mathrm{C}\right)$ the coffee was prepared following the Standardised protocol for filtered brewed coffee preparation in this paper. A plastic $10 \mathrm{~mL}$ syringe (BD Plastipak syringe) was used to transfer $10 \mathrm{~mL}$ of the brewed coffee from the paper-based cup into a ceramic cup and the ceramic cup was immediately placed on the ice bath. The temperature of the coffee in the ceramic cup was continuously monitored until it reached $22^{\circ} \mathrm{C}\left( \pm 2^{\circ} \mathrm{C}\right)$. For filter coffee, a $10 \mathrm{~mL}$ syringe (BD Luer-Lok Tip $10 \mathrm{~mL}$ syringe) was used to take up $4 \mathrm{~mL}$ of the coffee. A syringe filter was then placed on the syringe and $2 \mathrm{~mL}$ of the contents of the syringe was transferred to a clean ceramic cup. Using a $1 \mathrm{~mL}$ plastic pipette dropper $0.3 \mathrm{~mL}$ of the filter coffee sample was transferred into the sample well of the refractometer. The sample cover was closed and the sample was left for $20 \mathrm{sec}$ in the sample well to equilibrate to the temperature of the instrument. Then the \% TDS was obtained and recorded. A new filter and syringe was used for each measurement.

\subsection{Statistical Data Analysis}

The raw data accumulated from the trial was analysed using Microsoft Excel 2013 (Microsoft Corporation) and APLSR was used to process the data using Unscrambler software version 10.3. The X-matrix was designed as $0 / 1$ variables coffee samples and the Y-matrix sensory variables. To achieve significant results, regression coefficients were analysed based on cross-validation and stability plots [16]. Results showed significant differences of attributes among the different commercial filter and instant coffee samples. A map of the hedonic and descriptive sensory attributes was plotted using principal component analysis (PCA).

\section{Results and Discussion}

Data from coffee samples evaluated simultaneously using RAA and RDA meth- 
odologies are presented using APLSR plots (Figure 1 and Figure 2) and the corresponding ANOVA values for regression coefficients from APLSR for hedonic and intensity coffee terms assessed are presented in Table 3 and Table 4. Samples evaluated monadically (SAT and descriptive component) can be seen in Figure 3 and Figure 4 and Table 5 and Table 6 show the corresponding sensory hedonic and descriptive data obtained. The results from this study demonstrated that the simultaneous presentation of samples (in both the affective and descriptive components of this study) were more effective than monadic presentation. Additionally, a larger amount of attributes showed differences $(P<0.05)$ when presented simultaneously in comparison to when they were presented monadically (Tables 3-6).

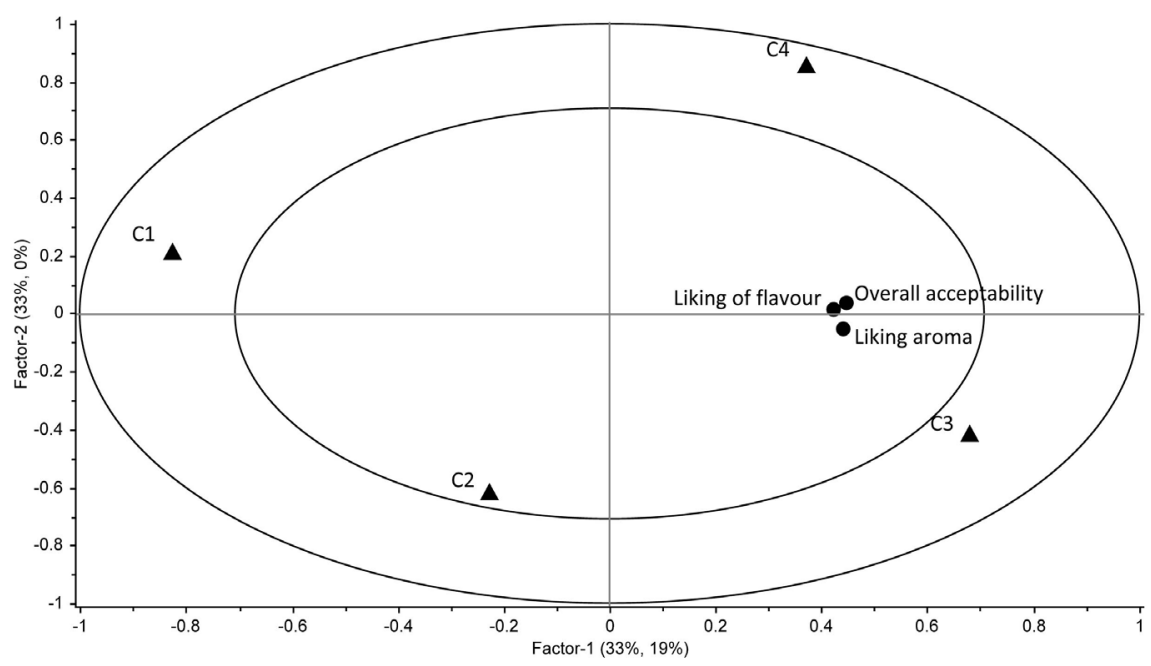

Figure 1. APLSR plot for the evaluation of the coffee samples assessed simultaneously by the RAA method. Shown are the loadings of the $\mathrm{x}$ - and $\mathrm{y}$-variables for the first 4 pcs for $\mathbf{\Delta}=$ individual treatments, $\bullet=$ sensory descriptor. PC 1 vs PC 2 presented.

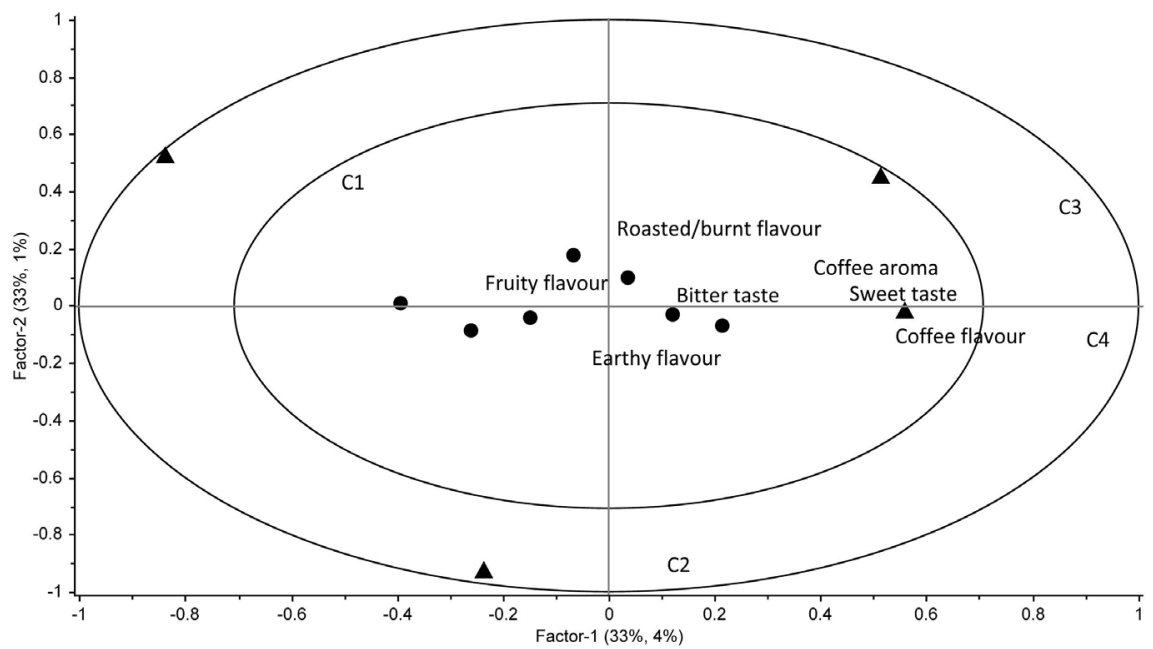

Figure 2. APLSR plot for the coffee samples assessed simultaneously by the RDA method. Shown are the loadings of the $\mathrm{x}$ - and $\mathrm{y}$-variables for the first 4 pcs for $\boldsymbol{\Delta}=$ individual treatments, $\bullet=$ sensory descriptor. PC 1 vs PC 2 presented. 


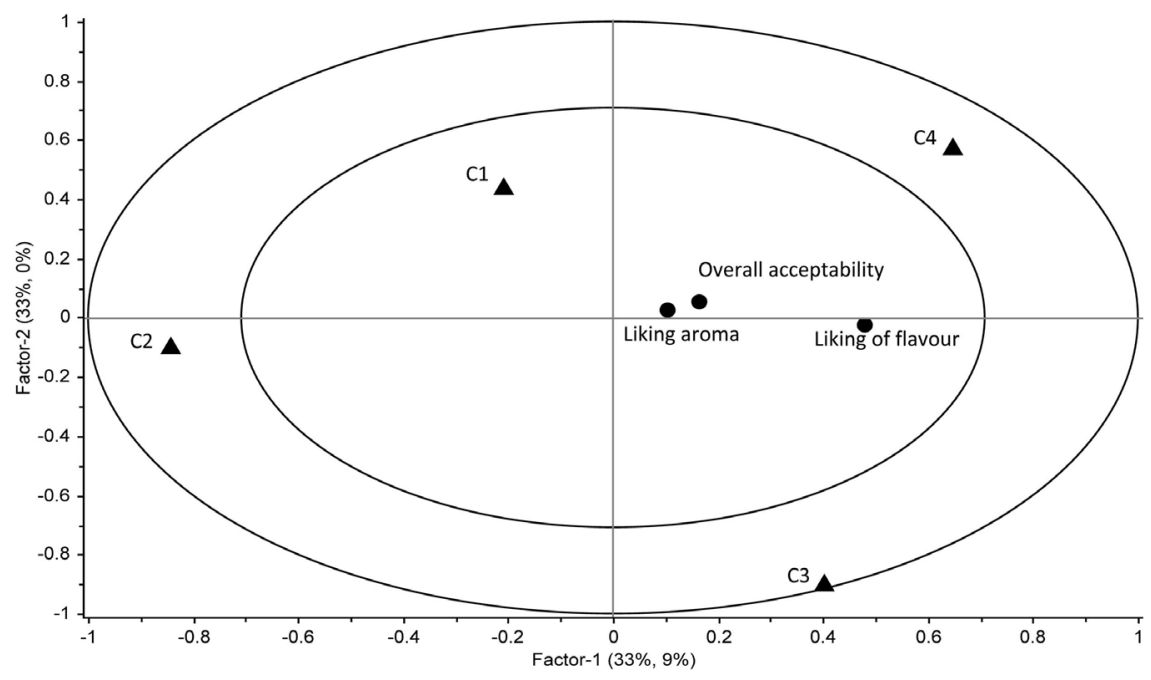

Figure 3. APLSR plot for the coffee samples presented monadically (affective). Shown are the loadings of the $\mathrm{x}$ - and $\mathrm{y}$-variables for the first 4 pcs for $\boldsymbol{\Delta}=$ individual treatments, $\bullet=$ sensory descriptor. PC 1 vs PC 2 presented.

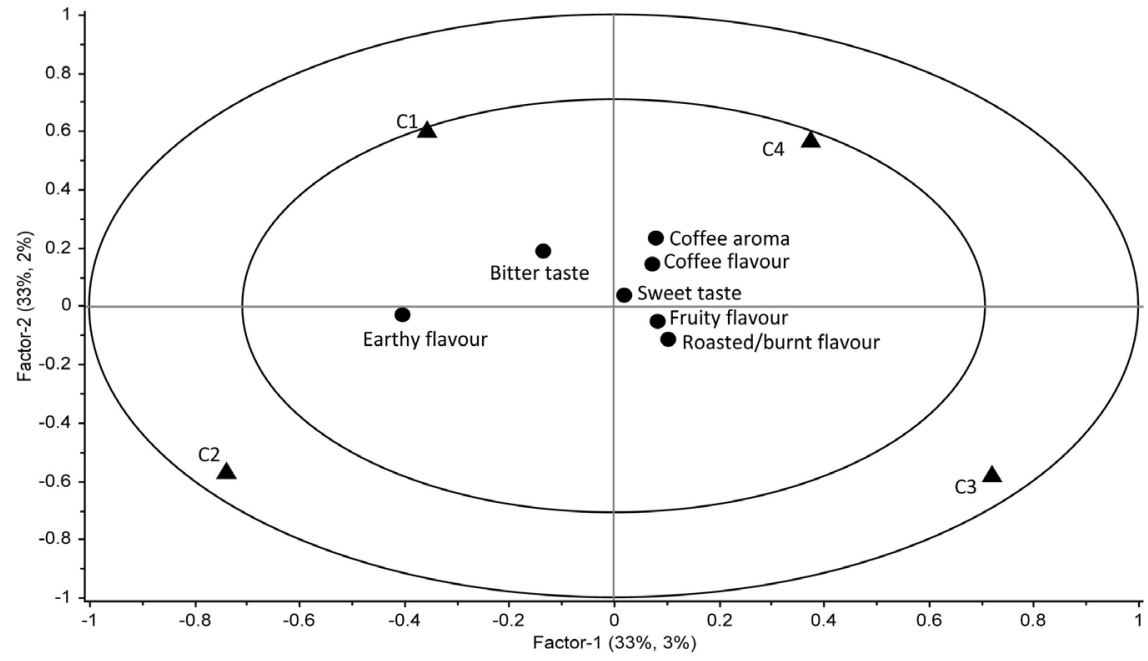

Figure 4. APLSR plot for the coffee samples presented monadically (descriptive). Shown are the loadings of the $\mathrm{x}$ - and $\mathrm{y}$-variables for the first 4 pcs for $\boldsymbol{\Delta}=$ individual treatments, - = sensory descriptor. PC 1 vs PC 2 presented.

Table 3. ANOVA values for regression coefficients from APLSR for simultaneous presentation of sample RAA data for coffee samples.

\begin{tabular}{cccc}
\hline & Liking aroma & Liking flavour & Overall acceptability \\
\hline C1 & $-0.000^{* * *}$ & $-0.000^{* * *}$ & $-0.000^{* * *}$ \\
C2 & $-0.223 \mathrm{~ns}$ & $-0.145 \mathrm{~ns}$ & $-0.021^{*}$ \\
C3 & $0.085 \mathrm{~ns}$ & $0.009^{* *}$ & $0.005^{* *}$ \\
C4 & $0.000^{* * *}$ & $0.000^{* * *}$ & $0.000^{* * *}$ \\
\hline
\end{tabular}

$P$-values are from the estimated regression coefficients from APLSR. The sign dictates whether the correlation is positive or negative. Significance of regression coefficients: $\mathrm{ns}=$ not significant, ${ }^{*}=P<0.050,{ }^{* *}=P$ $<0.01,{ }^{* * *}=P<0.001$. 
Table 4. ANOVA values for regression coefficients from APLSR for simultaneous presentation of sample RDA data for coffee samples.

\begin{tabular}{cccccccc}
\hline & $\begin{array}{c}\text { Coffee } \\
\text { aroma }\end{array}$ & $\begin{array}{c}\text { Coffee } \\
\text { flavour }\end{array}$ & $\begin{array}{c}\text { Roasted/burnt } \\
\text { flavour }\end{array}$ & $\begin{array}{c}\text { Earthy } \\
\text { flavour }\end{array}$ & $\begin{array}{c}\text { Fruity } \\
\text { flavour }\end{array}$ & $\begin{array}{c}\text { Sweet } \\
\text { taste }\end{array}$ & $\begin{array}{c}\text { Bitter } \\
\text { taste }\end{array}$ \\
\hline $\mathrm{C} 1$ & $-0.735 \mathrm{~ns}$ & $-0.002^{* *}$ & $-0.019^{*}$ & $0.010^{* *}$ & $0.000^{* * *}$ & $-0.049^{*}$ & $0.227 \mathrm{~ns}$ \\
$\mathrm{C} 2$ & $-0.102 \mathrm{~ns}$ & $-0.983 \mathrm{~ns}$ & $-0.046^{*}$ & $0.032^{*}$ & $0.391 \mathrm{~ns}$ & $-0.932 \mathrm{~ns}$ & $0.127 \mathrm{~ns}$ \\
$\mathrm{C} 3$ & $0.714 \mathrm{~ns}$ & $0.007^{* *}$ & $0.455 \mathrm{~ns}$ & $-0.042^{*}$ & $-0.007^{* *}$ & $0.201 \mathrm{~ns}$ & $-0.006^{* *}$ \\
$\mathrm{C} 4$ & $0.429 \mathrm{~ns}$ & $0.544 \mathrm{~ns}$ & $0.441 \mathrm{~ns}$ & $-0.004^{* *}$ & $-0.000^{* * *}$ & $0.692 \mathrm{~ns}$ & $-0.890 \mathrm{~ns}$ \\
\hline
\end{tabular}

$P$-values are from the estimated regression coefficients from APLSR. The sign dictates whether the correlation is positive or negative. Significance of regression coefficients: ns $=$ not significant, ${ }^{*}=P<0.050,{ }^{* *}=P$ $<0.01,{ }^{* *}=P<0.001$.

Table 5. ANOVA values for regression coefficients from APLSR for monadic presentation of the coffee samples.

\begin{tabular}{cccc}
\hline & Liking aroma & Liking flavour & Overall acceptability \\
\hline C1 & $-0.905 \mathrm{~ns}$ & $-0.088 \mathrm{~ns}$ & $-0.856 \mathrm{~ns}$ \\
$\mathrm{C} 2$ & $-0.110 \mathrm{~ns}$ & $-0.000^{* * *}$ & $-0.022^{\star}$ \\
$\mathrm{C} 3$ & $0.807 \mathrm{~ns}$ & $0.001^{* * *}$ & $0.798 \mathrm{~ns}$ \\
$\mathrm{C} 4$ & $0.251 \mathrm{~ns}$ & $0.000^{* * *}$ & $0.046^{*}$
\end{tabular}

$P$-values are from the estimated regression coefficients from APLSR. The sign dictates whether the correlation is positive or negative. Significance of regression coefficients: ns $=$ not significant, ${ }^{*}=P<0.050,{ }^{* *}=P$ $<0.01,{ }^{* * *}=P<0.001$.

Table 6. ANOVA values for regression coefficients from APLSR for monadic presentation of the coffee samples.

\begin{tabular}{cccccccc}
\hline & $\begin{array}{c}\text { Coffee } \\
\text { aroma }\end{array}$ & $\begin{array}{c}\text { Coffee } \\
\text { flavour }\end{array}$ & $\begin{array}{c}\text { Roasted/burnt } \\
\text { flavour }\end{array}$ & $\begin{array}{c}\text { Earthy } \\
\text { flavour }\end{array}$ & $\begin{array}{c}\text { Fruity } \\
\text { flavour }\end{array}$ & $\begin{array}{c}\text { Sweet } \\
\text { taste }\end{array}$ & $\begin{array}{c}\text { Bitter } \\
\text { taste }\end{array}$ \\
\hline C1 & $-0.282 \mathrm{~ns}$ & $-0.066 \mathrm{~ns}$ & $-0.162 \mathrm{~ns}$ & $0.079 \mathrm{~ns}$ & $-0.223 \mathrm{~ns}$ & $-0.443 \mathrm{~ns}$ & $0.011^{* *}$ \\
$\mathrm{C} 2$ & $-0.008^{* *}$ & $-0.014^{* *}$ & $-0.751 \mathrm{~ns}$ & $0.000^{* * *}$ & $-0.587 \mathrm{~ns}$ & $-0.417 \mathrm{~ns}$ & $0.826 \mathrm{~ns}$ \\
$\mathrm{C} 3$ & $0.167 \mathrm{~ns}$ & $0.970 \mathrm{~ns}$ & $0.030^{*}$ & $-0.000^{* * *}$ & $0.237 \mathrm{~ns}$ & $0.801 \mathrm{~ns}$ & $-0.000^{* * *}$ \\
$\mathrm{C} 4$ & $0.002^{* *}$ & $0.449 \mathrm{~ns}$ & $0.595 \mathrm{~ns}$ & $-0.001^{* * *}$ & $0.968 \mathrm{~ns}$ & $0.775 \mathrm{~ns}$ & $-0.513 \mathrm{~ns}$ \\
\hline
\end{tabular}

$P$-values are from the estimated regression coefficients from APLSR. The sign dictates whether the correlation is positive or negative. Significance of regression coefficients: ns $=$ not significant, ${ }^{*}=P<0.050,{ }^{* *}=P$ $<0.01,{ }^{* * *}=P<0.001$.

\subsection{Sensory Acceptance Testing}

For hedonic evaluation, both presentation methods (simultaneous and monadic) produced similar results. For both methods, samples $\mathrm{C} 1$ and $\mathrm{C} 2$ were negatively correlated to each of the hedonic attributes, and samples C3 and C4 were positively correlated to the hedonic attributes.

For the RAA method, a larger amount of significant results were obtained, with sample $\mathrm{C} 1$ being negatively correlated $(P<0.001)$ to liking of aroma, flavour and overall acceptability attributes. However, in comparison, in the mo- 
nadic method presentation, sample $\mathrm{C} 1$ had no significant results. For the RAA method, C2 was negatively correlated $(P<0.050)$ to overall acceptability. Similarly, the monadic presentation, sample $\mathrm{C} 2$ was negatively significantly correlated to overall acceptability, but also to liking of flavour. For the RAA method, samples $\mathrm{C} 3$ and $\mathrm{C} 4$ were positively correlated $(P<0.010)$ liking of flavour and overall acceptability. Sample $\mathrm{C} 4$ was also positively correlated $(P<0.001)$ to liking of aroma. In comparison, in the monadic presentation, samples $\mathrm{C} 3$ and $\mathrm{C} 4$ were positively correlated $(P<0.001)$ to liking of flavour, with $\mathrm{C} 4$ also being positively $(P<0.05)$ correlated to overall acceptability. Results from this study show that the RAA method displays a greater level of discrimination with this technique compared to traditional monadic presentation as is performed for SAT.

\subsection{Descriptive Testing Results and Discussion}

Simultaneous presentation and monadic presentation produced similar results for the descriptive attributes evaluated in this study but the results were not as consistent as was hedonic attributes. In the RDA method, sample $\mathrm{C} 1$ was negatively correlated $(P<0.05)$ to coffee flavour, roasted/burnt flavour and sweet taste and positively correlated $(P<0.010)$ to earthy flavour and fruity flavour. For the monadic presentation method, sample $\mathrm{C} 1$ was positively correlated $(P<$ $0.001)$ to bitter taste.

From Table 4 and Table 6 it is evident that for both methods (RDA and monadic), sample $\mathrm{C} 2$ was positively correlated $(P<0.05)$ to earthy flavour. In the RDA method, sample $\mathrm{C} 2$ was also negatively correlated $(P<0.05)$ to roasted/burnt flavour and in the monadic method sample $\mathrm{C} 2$ was also negatively correlated to this attribute, although not significantly. In the monadic method, sample $\mathrm{C} 2$ was negatively correlated $(P<0.05)$ to coffee aroma and coffee flavour.

For both the RDA method and the monadic presentation method, sample C3 was negatively correlated $(P<0.05)$ to earthy flavour and bitter taste. In the RDA method, the sample $\mathrm{C} 3$ was also positively significantly $(P<0.010)$ correlated to coffee flavour and negatively correlated $(P<0.05)$ to fruity flavour. For the monadic presentation method, sample C3 was positively correlated $(P<$ $0.05)$ to roasted/burnt flavour.

In the RDA method, sample $\mathrm{C} 4$ was negatively correlated $(P<0.010)$ to fruity flavour and earthy flavour. Similarly, for the monadic presentation method, C4 was negatively correlated $(P<0.050)$ to earthy flavour. C4 was also, positively correlated $(P<0.001)$ to coffee aroma in the monadic presentation method.

In this study, the RDA method resulted in a larger amount of significant differences in coffee intensity attributes compared to themonadic descriptive method employed. When you compare Tables 3-6 from this study, it is evident that RAA and RDA methodologies resulted in more significant differences being detected for product attributes compared to that generated through the employment of the monadic methods. 
Similar to data presented in this study, Pecore et al. [17] carried out a study on grain-based products using Spectrum Descriptive Analysis and their results showed that for both texture and flavour attributes, their assessor's ability to significantly differentiate small differences in attribute intensity was greater when using a ranked-scaling procedure.

Rodrigue et al. [18] compared conventional profiling to rank-rating profiling and they reported that both panels had the ability to discriminate between all samples, which again, is similar to the findings obtained in our study. In contrast however, they also reported slight inconsistencies generated by the panel employed, but this can be explained by the lack of training which the panellists received. These authors suggested that when people do not have enough time to train a panel for sensory analysis, they should consider using the ranking test. Richter et al. [1] assessed chocolate puddings using QDA, FCP and RDA and reported that the RDA method produced results similar to the results obtained using QDA and FCP.

Kim and O'Mahony [3] compared a traditional method of intensity scaling using ratings on a 9-point category scale to the rank-rating method using a 9-point category scale to determine which methodological approach provided results with the least amount of discriminatory error. Results from their studies showed that a significant majority of judges had fewer errors when using a Rank-rating method.

Da Silva et al. [19] compared three descriptive methods, which included; Optimized Descriptive Profile, Conventional Profiling and RDA using chocolate samples and they reported that all of the methods employed produced very comparable sensory profiles. Also, consumer orientated vocabularies have been developed for coffee by organisations such as ICO (International Coffee Organisation) [20]. However, the conventional approach to the sensory evaluation methods used for beverage assessment, such as coffee, are well established and defined [21] [22] [23], however sometimes these approaches do not include hedonic assessment always in conjunction with descriptive data. The use of hedonic evaluation methods like SAT in conjunction with rapid descriptive methods such as RDA is a powerful tool for the identification of positive and negative sensory drivers of liking ([24]-[32]) which traditionally have been elucidated using much more expensive and elaborate approaches such as internal and external preference mapping [32].

\section{Conclusion}

This study determined that assessors perceived the coffee samples similarly when using monadic or simultaneous presentation for both affective and descriptive methods. From the results generated in this study, it is evident that when coffee samples were presented simultaneously to panellists, a greater amount of attributes with significant $(P<0.05)$ intensity differences were observed for both affective and descriptive analysis. The RAA method displayed 
that all samples were significantly correlated for acceptability attributes with samples $\mathrm{C} 1$ and $\mathrm{C} 2$ being negatively correlated $(P<0.05)$ and samples $\mathrm{C} 3$ and C4 being positively correlated $(P<0.010)$ to these attributes. Thus, this method displayed a greater level of discrimination compared to traditional monadic presentation as is performed for sensory acceptance testing.

\section{Acknowledgements}

The research was part funded by Enterprise Ireland through the innovation partnership scheme with industrial support offered and supplied by Bewley's LTD. Bewley's Limited, Northern Cross, Malahide Road, Dublin 17, Ireland.

\section{References}

[1] Richter, V.B., de Almeida, T.C.A., Prudencio, S.H. and de Toledo Benassi, M. (2010) Proposing a Ranking Descriptive Sensory Method. Journal of Food Quality and Preference, 21, 611-620. https://doi.org/10.1016/j.foodqual.2010.03.011

[2] O’Sullivan, M.G. (2016) A Handbook for Sensory and Consumer-Driven New Product Development. Woodhead Publishing Ltd., UK.

[3] Kim, K. and O’Mahony, M. (1998) A New Approach to Category Scales of Intensity I: Traditional versus Rank-Rating. Journal of Sensory Studies, 13, 241-249. https://doi.org/10.1111/j.1745-459X.1998.tb00086.x

[4] Fellendorf, S., O’Sullivan, M.G. and Kerry, J.P. (2015) Impact of Varying Salt and Fat Levels on the Physiochemical Properties and Sensory Quality of White Pudding Sausages. Journal of Meat Science, 103, 75-82. https://doi.org/10.1016/j.meatsci.2014.12.010

[5] Fellendorf, S., O'Sullivan, M.G. and Kerry, J.P. (2016) Effect of Using Replacers on the Physicochemical Properties and Sensory Quality of Low Salt and Low Fat White Puddings. European Food Research and Technology Journal, 242, 2105-2118. https://doi.org/10.1007/s00217-016-2707-z

[6] Fellendorf, S., O’Sullivan, M.G. and Kerry, J.P. (2016) Effect of Different Salt and Fat Levels on the Physicochemical Properties and Sensory Quality of Black Pudding. Journal of Food Science and Nutrition (Online).

[7] Fellendorf, S., O’Sullivan, M.G. and Kerry, J.P. (2016) Impact of Using Replacers on the Physicochemical Properties and Sensory Quality of Reduced Salt and Fat Black Pudding. Journal of Meat Science, 113, 17-25. https://doi.org/10.1016/j.meatsci.2015.11.006

[8] O’Callaghan, T., Faulkner, H., Mcauliffe, S., O’Sullivan, M.G., Hennessy, D., Dillon, P., Kilcawley, K.N., Stanton, C. and Ross, P. (2016) Quality Characteristics, Chemical Composition, and Sensory Properties of Butter from Cows on Pasture versus Indoor Feeding Systems. Journal of Dairy Science, 99, 9441-9460.

https://doi.org/10.3168/jds.2016-11271

[9] Henneberry, S., O’Sullivan, M.G., Kilcawley, K.N., Kelly, P.M., Wilkinson, M.G. and Guinee, T.P. (2016) Sensory Quality of Unheated and Heated Mozzarella-Style Cheeses with Different Fat, Salt and Calcium Levels. Journal of Dairy Science, 69, 38-50. https://doi.org/10.1111/1471-0307.12300

[10] NCAUSA (National Coffee Association USA) (2016) How to Brew Coffee. http://www.ncausa.org/i4a/pages/index.cfm?pageID=71

[11] ISO (International Organization for Standardization) (2008) ISO 6668 Green Coffee 
- Preparation of Samples for Use in Sensory Analysis. ISO, Genève.

[12] Stone, H. and Sidel, J.L. (2004) Sensory Evaluation Practices. Academic Press/Elsevier, USA.

[13] Stone, H., Bleibaum, R.N. and Thomas, H.A. (2012) Sensory Evaluation Practices. 3rd Edition, Academic Press/Elsevier, USA.

[14] MacFie, H.J., Bratchell, N., Greenhoff, K. and Vallis, L.V. (1989) Designs to Balance the Effect of Order of Presentation and First-Order Carry-Over Effects in Hall Tests. Journal of Sensory Studies, 4, 129-148. https://doi.org/10.1111/j.1745-459X.1989.tb00463.x

[15] ISO (International Organization for Standardization) (2007) ISO 8589 Sensory Analysis-General Guidance for Design of Test Rooms. ISO, Genèva.

[16] Martens, H. and Martens, M. (2001) Multivariate Analysis of Quality. Wiley \& Sons, Chichester.

[17] Pecore, S., Kamerud, J. and Holschuh, N. (2015) Rank-Scaling: A New Descriptive Panal Approach for Rating Small Differences When Using Anchored Intensity Scales. Food Quality and Preference Journal, 40, 376-380. https://doi.org/10.1016/j.foodqual.2014.02.002

[18] Rodrigue, N., Guillet, M., Fortin, J. and Martin, J.-F. (2000) Comparing Information Obtained from Ranking and Descriptive Tests of Four Sweet Corn Products. Food Quality and Preference, 11, 47-54. https://doi.org/10.1016/S0950-3293(99)00063-4

[19] da Silva, R., Minim, V.P.R., Carneiro, J.D.S., Nascimento, M., Lucia, S.M.D. and Minim, L.A. (2013) Quantitative Sensory Description using the Optimized Descriptive Profile: Comparison with Conventional and Alternative Methods for Evaluation of Chocolate. Food Quality and Preference, 30, 169-179. https://doi.org/10.1016/j.foodqual.2013.05.011

[20] ICO (International Coffee Organisation) (2010) Consumer Orientated Vocabulary for Coffee. http://www.ico.org/vocab.asp?section=About_Coffee

[21] Kilcast, D. (2011) CH 11, Sensory Evaluation Methods for Food Shelf Life Assessment. In: Kilcast, D. and Subramaniam, P., Eds., Food and Beverage Shelf-Life and Stability, Woodhead Publishing Limited, Cambridge, 793-817. https://doi.org/10.1533/9780857092540.2.350

[22] O'Sullivan, M.G. (2017) CH 6, Shelf Life and Sensory Quality of Foods and Beverages. A Handbook for Sensory and Consumer Driven New Product Development: Innovative Technologies for the Food and Beverage Industry. Woodhead Publishing Ltd., Cambridge, 103-123.

[23] O’Sullivan, M.G. (2017) CH 13, Sensory Properties of Beverage Products. A Handbook for Sensory and Consumer Driven New Product Development: Innovative Technologies for the Food and Beverage Industry. Woodhead Publishing Ltd., Cambridge, 281-304. https://doi.org/10.1016/B978-0-08-100352-7.00013-0

[24] Stokes, C., O’Sullivan, M.G. and Kerry, J.P. (2016) Assessment of Black Coffee Temperature Profiles Consumed from Paper-Based Cups and Effect on Affective and Descriptive Product Sensory Attributes. International Journal of Food Science and Technology, 51, 2041-2048. https://doi.org/10.1111/ijfs.13176

[25] Stokes, C., O’Sullivan, M.G. and Kerry, J.P. (2017) Hedonic and Descriptive Sensory Evaluation for Development of Novel Instant and Fresh Coffee Products. European Food Research and Technology, 243, 331-340. https://doi.org/10.1007/s00217-016-2747-4

[26] Bertuzzi, A.S., Kilcawley, K.N., Sheehan, J.J., O’Sullivan, M.G., Kennedy, D., 
McSweeney, P.L.H. and Rea, M.C. (2017) Use of Smear Bacteria and Yeasts to Modify Flavour and Appearance of Cheddar Cheese. International Dairy Journal, 72, 44-54. https://doi.org/10.1016/j.idairyj.2017.04.001

[27] Cavanagh, D., Kilcawley, K.N., O’Sullivan, M.G., Fitzgerald, G.F. and McAuliffe, O. (2014) Assessment of Wild Non-Dairy Lactococcal Strains for Flavour Diversification in a Mini Gouda Type Cheese Model. Food Research International, 62, 432-440. https://doi.org/10.1016/j.foodres.2014.03.043

[28] O’Callaghan, T., Mannion, D.T., Hennessy, D., McAuliffe, S., O’Sullivan, M.G., Leeuwebdaal, N., Beresford, T.P., Dillon, P., Kilcawley, K.N., Sheehan, D.J., Ross, P. and Stanton, C. (2017) Effect of Pasture versus Indoor Feeding Systems on Quality Characteristics, Nutritional Composition, and Sensory and Volatile Properties of Full-Fat Cheddar Cheese. Journal of Dairy Science, 100, 6053-6073. https://doi.org/10.3168/jds.2016-12508

[29] Walsh, A., Crispie, F., Kilcawley, K.N., O’Sullivan, O., O’Sullivan, M.G., Claesson, M. and Cotter, P. (2016) Microbial Succession and Flavour Production in the Fermented Dairy Beverage Kefir. mSystems, 1, e00052-16.

https://doi.org/10.1128/mSystems.00052-16

[30] Yarlagadda, A., Wilkinson, M.G., Ryan, S, Doolan, A.I., O’Sullivan, M.G. and Kilcawley, K.N. (2014) Utilisation of a Cell Free Extract of Lactic Acid Bacteria Entrapped in Yeast to Enhance Flavour Development in Cheddar Cheese. International Journal of Dairy Science Technology, 67, 21-30.

https://doi.org/10.1111/1471-0307.12099

[31] Yarlagadda, A., Wilkinson, O’Sullivan, M.G. and Kilcawley, K.N. (2014) Utilisation of Microfluidisation to Enhance Enzymatic and Metabolic Potential of Lactococcal Strains as Adjuncts in Gouda Type Cheese. International Dairy Journal, 38, 124-132. https://doi.org/10.1016/j.idairyj.2014.01.007

[32] O’Sullivan, M.G. (2017) CH 5, Multivariate Data Analysis. A Handbook for Sensory and Consumer Driven New Product Development: Innovative Technologies for the Food and Beverage Industry. Woodhead Publishing Ltd., Cambridge, 83-99.

https://doi.org/10.1016/B978-0-08-100352-7.00005-1 